\title{
O hospital universitário e as tendências atuais na educação médica
}

\author{
Juan Stuando Yazlle Rocha(*)
}

"Ảs vezes é necessário mudar alguma coisa para que nada se modifique."

Lampedusa

A colocação em discussão em fins de 1978, no Conselho Universitário da Universidade de São Paulo, do projeto de Estatuto para Fundação do Hospital Universitário e as reações levantadas pelo mesmo, desde diferentes perspectivas, chamam a atenção da coletividade universitária para problemas gerais do Ensino, Assistência e Investigação na área da Saúde.

A estrutura de Fundação permitiria a flexibilidade suficiente para estabelecer convênios de prestação de serviços que aliviariam a carga financeira do Estado, ao mesmo tempo que dariam representatividade social à composição da demanda que alcança a instituição. Para outros, a Fundação é expressão de uma tendência assistencialista, que, em si mesma, significa abaixar o nivel da investigação médica e conseqüentemente, a queda do nivel do Ensino Médico. Para outros, enfim, a flexibilidade administrativa desde que não comprometida com os problemas de saúde da população circunvizinha, e pela não incorporação no proje-

(*) Departamento de Medicina Social da Faculdade de Medicina de Ribeirão Preto da USP to do Centro de Saúde Escola, representaria a subordinação do Hospital Universitário aos interesses da "indústria da saúde".

A discussão de modelos alternativos da estrutura para Hospitais Universitários deve começar, ao nosso ver, pela discussão do modelo de Ensino Médico, dentro do qual, as atividades desenvolvidas no âmbito hospitalar, são apenas uma parte. O modelo do Ensino Médico dominante na Universidade de São Paulo (Faculdade de Medicina de Pinheiros e de Ribeirão Preto) é ainda o modelo flexneriano.

Assim, é necessário discutir, à luz da contribuição da experiência já adquirida, o significado do dito modelo, nos tempos atuais, quase 70 anos após a publicação do relatório Flexner.

A Fundação Carnegie para o Progresso do Ensino, nos EUA, patrocinou um estudo sobre as condições do ensino médico, o qual foi realizado por Abraham Flexner e publicado pela primeira vez em 1910 com o titulo "Medical Education in the United States and Canada" (1). Este relatório veio influenciar o ensino médico em todo o continente e até na Europa. Suas recomendações passaram a constituir os predicados básicos de uma boa escola de Medicina. Sua influência foi decisiva, nos EUA, na vitória da medicina alopática sobre a medicina homeopática, que predominava ampla- 
mente naquele pais no inicio do século. Naquela época, o trabalho da Fundação Carnegie se orientava a promover o "cientificismo" (positivismo) em todos os setores sociais: administração cientifica, agricultura cientifica, educação progressiva, e a medicina "cientifica". Em todos estes setores, os problemas sociais, que exigiam respostas politicas, eram transformados, pela perspectiva de análise adotada, em problemas "cientificos", de solução tecnológica, portanto. Esta posição ideológica da Fundação Carnegie estava perfeitamente consoante com a necessidade, naquele momento histórico, de desfazer as tensões sociais decorrentes da urbanização e desenvolvimento capitalista nos EUA e acenar com a possibilidade de resolução técno-científica dos problemas sociais e chegar assim, pelo modelo capitalista, a estender o progresso a toda a população.

Por influência do Relatório Flexner o ensino médico foi trazido ao interior das universidades, foi definido um curriculum minimo de 4 anos de duração, introduziram-se atividades de investigação dentro do programa de ensino (binômio ensino-pesquisa) e exercícios práticos de laboratório, recomendou-se o tempo integral como regime de trabalho para as escolas médicas, dividiu-se o curriculum em um ciclo básico e um ciclo clínico. Mudanças conceituais também foram introduzidas: adota-se um modelo que considera o corpo humano como máquina, dando lugar à abordagem instrumentalista do mesmo; passa-se a enfatizar o estudo de sistemas ou órgãos isolados, excluindo a visão da totalidade do corpo; a enfermidade é tratada como um processo natural (biológico) excluindo a causalidade social, a qual será alienada do diagnóstico e terapêutica. A nova medicina "cientifica" volta sua atenção para o individuo ou subindividuo (célula ou órgão) o que não somente mascara a relação da doença com o ambiente externo (social) senão que centra a investigação curativa e preventiva sobre o individuo mais que sobre a coletividade. $O$ hospital universitário, flexneriano, é primordialmente uma instituição de investigação biologicista que concentra os recursos cientifico-tecnológicos mais avançados, e mais, ainda, que através da sua investigação desenvolve cada vez mais as técnicas instrumentalistas de intervenção sobre o individuo parcelado, principalmente no interior (intramuros) da organização. Por causa disto o hospital universitário tem uma estrutura peculiar com duplicidade de linha de mando: uma, a linha administrativa, a cargo da estrutura administrativa e outra, a cargo dos Departamentos ou Clinicas, responsável pela Assistência, Ensino e Investigação; alèm disto, o que é pior, cada Departamento ou Clinica tem autonomia nas suas áreas de responsabilidade, o que acarreta numerosas distorções institucionais, a mais grave delas é que o hospital não tem necessariamente uma politica assistencial de ensino e/ou de investigação única senão uma somatória de "politicas" particulares de cada clinica.*

Não cabe a nós julgar qual tenha sido a influência do Relatório Flexner na Assistência e Investigação médica no Brasil. Podemos constatar, no entanto, que desde a publicação do mesmo até agora, ocorreram importantes transformações nas estruturas sociais globais, no continente, e em aspectos especificos que dizem respeito às escolas médicas.

\footnotetext{
* Vale assinalar que essa tendência já foi sentida nos hospitais de ensino recém-inaugurados no Brasil, os quais obedecem à orientação técnico-administrativa unificada, na linha de objetivos a serem alcançados.
} 
Assim, o desejo de manter certas caracteristicas do modelo flexneriano deve significar, no minimo, o estudo destas transformações e a readaptação do modelo às condições atuais da assistência e do ensino médico.

A medicina "cientifica" provocou, no espaço de poucas décadas, um grande desenvolvimento tecnológico (instrumentos, equipamentos, etc.) que mediando o ato médico o tornaram cada vez mais caro, complexo e sofisticado. A elevada quantidade de recursos exigidos para a implantação da infra-estrutura necessária à assistência médica moderna, fez com que a mesma só se desenvolvesse nos centros populacionais de maior poder economico, dali irradiando-se a centros menores, em diferentes niveis de complexidade. Desta forma as instituições prestadoras de serviços estruturaram-se em niveis assistenciais segundo a sua disponibilidade de recursos; identificaram-se os niveis: primário, de medicina geral; secundário, de especialistas; terciário, de super-especialistas (especialistas-especializados). A disposição dos serviços de saúde em niveis de complexidade é comum a todos os paises americanos e passou a ser conhecida como Regionalização Assistencial (2).

O Hospital Universitário flexneriano, centro por excelência de investigação clinica de alto padrão, configura em muitos casos a instituição de nivel terciário de assistência, centro regional, ou nacional, no caso de paises de menor extensão territorial. Para este centro passam a ser drenados os casos de dificil diangóstico ou que requeiram recursos terapêuticos complexos. Os casos mais simples, a grande maioria dos problemas de saúde prevalentes na população, são satisfatoriamente atendidos nos niveis primário ou secundário do sistema, a um custo operacional muito menor. A racionaliza- ção dos recursos consiste, neste caso, em adequar o nivel dos recursos às necessidades, concentrando os recursos mais complexos e de maior custo operacional, no centro regional ou nacional, para dar cobertura a uma população maior.

Do ponto de vista dos sistemas sociais de Assistência Médica, importantes mudanças ocorreram no pais nas últimas décadas. A Previdência Social, que tem inicio em 1923 com a Lei Elói Chaves, estende-se a várias categorias de assalariados urbanos, na década seguinte (IAP's) e adquire grande desenvolvimento com a urbanização $\mathrm{e}$ industrialização crescentes nas décadas de 40 e 50 . A década de 50 corresponde ao periodo em que se gesta a chamada "revolução de expectativas" pela qual grandes camadas da população tomam conhecimento das transformações e avanços do mundo moderno e passam a exigir seus direitos na participação dos frutos do progresso, estando ai incluida, principalmente, a assistência médica. O crescimento da demanda de serviços de saúde pressiona a expansão da rede dos mesmos, levando a uma intervenção cada vez maior do Estado na assistência médica; a partir de 1966 a politica previdenciária torna-se dominante no setor saúde, em relação a politica da saúde pública que até então tinha predominado. Implanta-se definitivamente, no pais, um modelo de assistência médica, predominantemente curativa, superespecializada, altamente tecnificada e dependente da chamada "indústria da saúde". Esta medicina, apesar dos seus altos custos, tem efeitos reduzidos (ou até discutiveis) em relação aos problemas de saúde coletivos. Critica-se não apenas a incapacidade em resolver os problemas de saúde prioritários, mas também quanto ao possivel efeito adverso sobre a população (iatrogênese clínica, social e estrutural de Illich) (3). Des- 
taque-se que o surgimento do modelo assistencial acima descrito é apenas o efeito de uma determinada concepção da saúde-enfermidade favorecida por uma estrutura social que converte os atos médicos em mercadoria (4).

A Educação Médica, tradicionalmente, visava a preparação tecnocientifica do aluno para o exercício médico liberal, que era a prática profissional dominante até meados da década dos 60 . O ensino médico se centrava em uma prática discente eminentemente hospitalar, já fosse em hospital universitário ou em hospital assistencial comunitário. Com as transformações ao nível da prática médica, acima assinaladas, tornou-se evidente a necessidade de adequar o ensino à prática médica, isto é, preparar o aluno para as condições de trabalho profissional que ele iria encontrar no futuro, dando-lhe uma visão critica das mesmas. Seria desejável, portanto, incorporar às práticas discentes os sistemas sociais de assistência médica existentes, ou ao menos aqueles dominantes (medicina previdenciária, saúde pública, etc.), e desenvolvêlas em condições e niveis de assistência semelhantes aos de sua futura prática, quer dizer, serviços de saúde de nivel primário e secundário principalmente, sem contudo, excluir o nivel terciário. Propõe-se substituir o Hospital Universitário, regional, superespecializado, como campo predominante da prática discente, por uma rede de serviços de saúde, com ênfase nos dois primeiros niveis; é a chamada Regionalização Docente-Assistencial $(2,5,6)$. Nos últimos anos da década dos 60 , nos EUA, a Fundação Carnegie patrocinou um novo estudo sobre o Ensino Médico, o qual foi publicado em 1970. Este novo informe "põe em dúvida a validade do Informe Carnegie inicial, escrito pelo Dr. Flexner em 1910, no sentido de que as investigações bioló- gicas constituam a base da educação médica, afirmação que não seria aplicável hoje em dia" (7). Passa-se então a difundir a idéia que é necessário substituir o binômio "ensino-pesquisa" pelo binômio "ensino-assistência". Nos primeiros anos da década de 70 várias experiências de ensino médico adotam este novo enfoque, tanto nos ÉUA como na América Latina.

A pressão principal e que, provavelmente será decisiva para o futuro dos Hospitais Universitários, não provém das novas tendências no Ensino Médico, ou na Assistência Médica, e nem da consciência que um novo tipo de investigação em saúde torna-se prioritário nos últimos tempos, pressões estas que podem ser facilmente controladas ou simplesmente ignoradas. A pressão decisiva vem pela contradição de ser o Hospital Universitário um hospital de custo elevadissimo e ao mesmo tempo "fechado" para a coletividade (requisito flexneriano para uma boa investigação e portanto um bom nivel de ensino). Os custos de construção e manutenção do Hospital Universitário saem sempre da coletividade, não importa que finalmente apareçam como verbas federais, estaduais ou municipais. E sabido que os custos de assistência médica crescem três vezes mais rapidamente que o custo de vida, nos países ocidentais. Os custos do Hospital Universitário, como instituição lider do sistema, devem crescer mais rapidamente ainda tornando seu financiamento altamente problemático. Lembremos que o Estado capitalista monopolista é um Estado em crise fiscal (tendência de seus gastos crescerem mais rapidamente do que suas receitas) por maior que seja sua participação nos gastos (os gastos públicos no Brasil em 1975 representavam $40 \%$ do PIB). A tendência do Estado nesta situação, tem sido a de gastar cada vez menos nos setores sociais 
(8). Portanto, o financiamento desta instituição privilegiada é o seu calcanhar de Aquiles diante de pressões sociais que acabam canalizadas politicamente.

Enfim, podemos dizer que a preservação de uma filosofia de ensino e investigação, marcadamente flexnerianos, entra em contradição com as tendências atuais do setor saúde no pais, e com as tendências do ensino médico na maioria dos paises americanos. A ruptura deste "modelo" pelas pressões sociais (e politicas) poderá acarretar o fim dos aspectos positivos que ele contém se não se proceder a uma reavaliação do significado da experiência flexneriana, suas contribuições no passado e presente, e a necessidade de readaptação às transformações das últimas décadas. Os projetos "alternativos" que surgem (incluidas as propostas de Estatutos), significam muito mais a viabilização da manutenção do "status quo" educacional do que um empreendimento novo, no sentido que as mudanças sociais reclamam.

\section{Referências Bibliográficas}

1. BERLINER, H. S. - A Larger Perspective or the Flexner Report. International Journal of Health Services 5(4): 573-92, 1975.
2. BOBENRIETH, M. A. et alii - "Nuevos enfoques en organización administración de hospitais de enseñanza; organización matriz, atención progressiva de pacients, e historias clinicas orientadas a problemas". In: "Seminário sobre Hospitais de Ensino", Rio de Janeiro, 1975. Trabalhos Apresentados.

3. CHAVES, M. - Regionalização Docente-Assistencial e Niveis de Assistência. In: "Seminário sobre Hospitais de Ensino", Rio de Janeiro, 1975. Trabalhos Apresentados.

4. FARRIER, R. M. - La Función del hospital en la educación médica en los Estados Unidos. Educacion Médica y Salud, (2): 137-147, 1972.

5. FERREIRA, J. R. - O Papel do Hospital Á Luz das Novas Tendências do Ensino Mèdico. In: Seminário sobre Hospitais de Ensino, Rio de Janeiro, 1975. Trabalhos Apresentados.

6. ILLICH, I. - Nemesis Médica; La expropiación de la Salud. Barral Barcelona, Editores, 1975.

7. NAVARRO, V. - The Industrialization of Fetishism or the Fetishism of Industrialization; a critique of Ivan Illich. International Journal of Health Services 5(3): 351-71, 1975.

8. SOUZA, H \& AFONSO, C. A. - El papel del Estado en el desarrolo capitalista; la crisis fiscal del Estado brasileiro. Colección América Latina. Fac. de Economia. UNAM, México, 1977. 